\title{
DELIBERACIÓN Y CONFIANZA EN EL MUNDO. SOBRE MORALITY, SELF-KNOWLEDGE AND HUMAN SUFFERING, DE JOSEP CORBÍ
}

Josep E. Corbí, Morality, Self-Knowledge and Human Suffering. An Essay on The Loss of Confidence in the World, Routledge, Londres (Routledge Studies in Contemporary Philosophy, 38), 2012, 254 pp.

FERNANDO BRONCANO Departamento de Humanidades: Filosofía, Lenguaje y Literatura Universidad Carlos III de Madrid Fernando.Broncano@uc3m.es

Éste es un libro sobre la distancia reflexiva y la ceguera moral. Josep Corbí nos propone una novedosa contribución a la larga controversia sobre el constructivismo en teoría moral con un argumento de adscripción particularista que implica varias importantes consideraciones metaéticas. El particularismo, como es bien conocido, sostiene que las propiedades morales de una acción no son ejemplificaciones de principios generales (Dancy 2009, p. 1), y que, por consiguiente, el juicio moral no exige necesariamente la aplicación de principios a la descripción de la acción para discernir su carácter moral. Es una reacción al kantismo que sostiene la indispensabilidad de los principios en cuanto constituyentes del juicio moral. Para "tener un caso" (empleando la metáfora jurídica anglosajona), Corbí necesita, en primer lugar, una caracterización creíble de la posición kantiana; en segundo lugar, evidencia razonable de que dicha posición no consigue su fin de dar cuenta del juicio moral con respecto a los contraejemplos; en tercer lugar, si la tesis pretende un alcance largo en teoría moral, el momento crítico debería abrir una fase constructiva con una propuesta alternativa intuitivamente aceptable. Aunque el espectro de autores kantianos es muy amplio, Corbí se centra en las versiones de Christine Korsgaard y John Rawls. El crítico no convencido, por su parte, podrá aducir que la posición kantiana no está caracterizada con suficiente fidelidad, que la evidencia aducida no es suficiente $o$, quizá, que la posición alternativa es mucho menos creíble que la que está en el banquillo. Mi lectura del libro no ha observado ninguno de estos fallos (aunque es muy posible que una lectura ortodoxa- 
mente kantiana pudiera contradecirme). Por el contrario, considero que el libro consigue un buen argumento antikantiano y abre una perspectiva original e intrigante. Las mayores aportaciones del libro están en sus finos análisis de los casos morales invocados, que aportan penetrantes consideraciones sobre la estructura del daño, como base del juicio moral, y, en segundo lugar, en sus prescripciones metaéticas sobre el carácter de la escritura en filosofía moral. Corbí logra en esta obra un paso sustancial en el programa particularista, un argumento al que los kantianos no pueden no responder y, sobre todo, un ejercicio de epistemología moral de incontestable relevancia metodológica y, añadiría, moral, tanto para el filósofo como para el lego en problemas de ética.

Un agente moral es, desde un punto de vista kantiano, una "persona de principios", es decir, una persona capaz de convertir las razones de su acción en máximas generalizables o leyes a las que somete su acción. La normatividad de la acción no está en el puro hecho de que la acción se defina por un objetivo, sino en que su misma definición pueda convertirse en un principio. Esta normatividad es, para esta concepción, la frontera real de lo humano en el mundo. El kantiano alega que esta normatividad inyecta "necesidad" en la pura contingencia de la acción. El segundo componente de la concepción kantiana es que esta necesidad proviene de la autoconstitución del agente como agente moral o, dicho con términos más tradicionales, de la autonomía del agente. Es decir, la actuación bajo máximas es al tiempo la forma de adquisición de una identidad moral. El argumento que desarrolla Corbí tiene por objetivo convencernos de que la promesa kantiana solamente se puede llevar a cabo introduciendo formas de dualismo que a) vuelven inconsistente el proyecto y b) lo convierten en moralmente improductivo. La argumentación se desenvuelve en tres movimientos: en el primero, examina el dualismo en el dispositivo que permite a un sujeto elaborar un juicio moral; en el segundo, examina el dualismo en la misma fábrica del sujeto moral; en el tercero, propone la atención y la conciencia expresiva frente a la reflexión y la conciencia declarativa. En resumen, un sujeto sensible y perceptivo frente a un sujeto de principios. Mi acuerdo sustancial con el libro no evita, sin embargo, que pregunte si su solución no será aún demasiado dependiente de una dicotomía entre primera y tercera personas y poco perceptiva de la necesidad de la segunda persona en la mirada moral. 


\section{El problema de la distancia: los desapegos del sujeto moral}

El dispositivo ${ }^{1}$ que, para la tradición kantiana, permite al agente deliberar y juzgar correctamente es ponerse en el lugar del otro en ciertas condiciones que hacen posible que el juicio resultante adquiera la categoría de máxima. Corbí elige la versión rawlsiana, la cual consiste en dos demandas: razonar en la "posición original" y emitir un juicio que pase el control del "equilibrio reflexivo". En este modelo se suponen únicamente ciertas condiciones mínimas de agencia moral: ser racional y poseer cierto sentido de la justicia y el bien. A tales agentes se les pide ponerse en una situación hipotética donde se ignoren las características de constitución biológica o posición social del interesado, y, en semejantes condiciones, elaborar un juicio al que pueda asentir dadas sus intuiciones como agente. Corbí argumenta que, de entrada, el mecanismo solamente puede funcionar si supone una distinción — no explícita en Rawls - entre los juicios acerca de situaciones que el agente no ha experimentado y juicios acerca de situaciones de las que el agente tiene experiencia: juicios hipotéticos y juicios efectivos. En segundo lugar, el dispositivo exige, aduce Corbí, un supuesto de concordancia (Corbí 2012 p. 14) entre los juicios hipotéticos y los juicios efectivos, suponiendo que el razonamiento se desarrolle correctamente.

Cabría esperar que, con este punto de partida, Corbí negase la convergencia de juicios y hipotéticos y reales añadiendo así un argumento más a los muchos críticos de la demanda liberal y constructivista de imparcialidad y neutralidad (Benhabib y Cornell 1987; Benhabib 1992). Ciertamente, Corbí critica este supuesto de convergencia que supone y exige un agente capaz de distanciarse de la situación particular. Todos los críticos del constructivismo han entendido que esta distancia produce déficits de visión de los componentes morales de la situación, posición que también Corbí comparte. Sin embargo, su análisis no se basa en la usual distinción entre un "otro concreto" y un "otro generalizado" tan extendida entre aquellos. Tal distinción se aplica generalmente a un análisis bipartito <sujeto, situación $>$ del proceso deliberativo (puesto que el agente debe "ponerse en el lugar del otro en esa situación), mientras que Corbí propone un modelo tripartito <sujeto, situación, tercer agente> que le permite abordar los mecanismos de ceguera producidos por la distancia sin suponer fallos en el proceso generalizador, como ocurre en todos los adherentes a la distinción "concreto/generalizado". Los fallos en el dispositivo

${ }^{1}$ El término "dispositivo" es el que Rawls elige para definir su modelo: "an expository device” (Rawls 1999, p. 19, citado en Corbí, 2012, p. 15). 
generalizador, tal como lo entienden los críticos, se basan de un modo $\mathrm{u}$ otro en suponer una especie de standpoint o privilegio epistémico del otro concreto que se pierde en el caso del otro generalizado. Pero esta estrategia tiene poco recorrido puesto que el kantiano se siente respaldado en una exigencia de normatividad de los juicios, a la que el crítico sustentado en el privilegio epistémico no es capaz de responder adecuadamente.

La presencia del tercer agente es fundamental en la estrategia del libro. Nace del examen de varios ejemplos a los que nos referiremos más adelante. Sostiene que esos casos de daño no pueden ser analizados bajo la simple luz de un sujeto y una situación. El examen de estas situaciones debería hacer aflorar la necesaria presencia de terceros agentes que tendrían que haber estado allí para impedir el daño, o que deberían comprometerse a reconocerlo y hacer justicia y que, sin embargo, la referencia a aquéllos desaparece cuando el razonamiento deliberativo se produce en condiciones de abstracción de los detalles de la circunstancia. El tercer agente tendría que operar como un contradispositivo que anclaría al sujeto deliberante en los matices de la situación particular que se examina y, que, si no es tenido en cuenta, no es por un deseo de imparcialidad sino por un submecanismo de alejamiento y falta de compromiso con la víctima. El mordiente de su objeción nace de la misma estructura del proceso deliberativo. Su punto es que, al incorporar a terceros agentes, el razonamiento regresa a la situación examinada. Pretender evitar este anclaje en lo particular causa una debilidad seria en la producción del juicio moral. No sólo importa la condición del otro sino también los caracteres finos de la situación donde se ha quebrado y convertido en víctima. El tercer agente puede ser leído como un puro recurso que aporta una contraevidencia al supuesto de concordancia o, en una versión más interesante de la tesis de Corbí, como un auténtico contradispositivo presente en la deliberación que conduce al juicio moral. En este caso, Corbí nos debe aún algo más sobre la naturaleza de este tercer agente. Más adelante abordaremos esta duda. Pero la interpretación como recurso crítico ya es interesante en sí misma.

La estrategia de Corbí descansa en la hipótesis de que la resistencia a incorporar un tercer agente presente en la situación de daño se produce porque los rasgos concretos de la situación particular entrañarían una demanda que el sujeto deliberante no está dispuesto a cumplir. Cuando la mirada pública de terceras partes se incorpora a la deliberación, la distancia se derrumba y la situación examinada crea una disonancia cognitiva que produce una negación de la existencia de esa mirada. ¿Qué es lo que tiene la situación particular para 
producir este efecto? La respuesta kantiana tendría que ser que la situación por sí misma no tiene tales capacidades, pues es solamente el sujeto quien, mediante su juicio, correcto o erróneo, calibra los rasgos morales de la situación. Suponiendo que esa pudiera ser la respuesta plausible, Corbí dedica el núcleo más sustancioso de su trabajo a explicitar los supuestos ontológicos por los que una respuesta de este tipo implica una devaluación de las capacidades epistémicas del sujeto deliberante.

En primer lugar, considera que una de las razones por las que el constructivismo rechaza las virtualidades de las situaciones particulares es por su compromiso con una concepción del mundo que no admite que la realidad pueda poseer propiedades morales. Las propiedades morales son proyecciones del sujeto sobre lo real. Corbí observa que quienes comparten esta convicción no realista acerca de las propiedades morales comparten también una concepción que califica de bipartita y cientificista entre el mundo - completado exhaustivamente por propiedades físicamente causales - y las propiedades mentales $\langle M, \Psi\rangle$. Los valores no pertenecen al mundo sino a las mentes. Pero entonces, ¿cómo es posible considerar el daño como algo real que involucra la no respuesta de terceros agentes? El argumento de Corbí es que no es posible sin que el deseo de objetividad y la concepción bipartita entren en colisión. Una respuesta constructivista como el "realismo procedimental" de Korsgaard podría buscar una compatibilidad entre la concepción bipartita y el objetivismo mediante una doble estrategia: a) considerar los valores como propiedades dependientes de respuesta (siguiendo la estrategia de Lewis 1989), b) añadir al disposicionalismo una condición normativa de objetividad como el "asentimiento reflexivo" (reflective endorsement). La primera condición nos conseguiría el compatibilismo y la segunda el objetivismo.

Corbí opone a esta estrategia una objeción de cierto aroma wittgensteiniano y pragmatista (véase la controversia planteada en Putnam y Habermas 2008). Para cerrar el camino a una solución disposicionalista de los valores argumenta que no podemos construir un valor (Corbí hace uso aquí de la artillería semántica de "individuación" del contenido), al modo "dependiente de respuesta", como un duplo <propiedad poseída por una situación, disposición en un sujeto a una reacción $>$ porque las propiedades morales, sostiene, solamente pueden introducirse holísticamente, aludiendo a otros conceptos o propiedades morales que cumplen ciertas constricciones que Corbí califica como "disciplina narrativa". Sostiene que, aunque un término como "asqueroso" pudiera construirse como una disyunción 
de objetos que producen una reacción de asco, un término moral como "humillante" no podría seguir esta senda. Para describir una situación como humillante debemos emplear una red de términos que tienen ya un contenido moral y, además, hacerlo en el marco de cierta disciplina narrativa que alude a un complejo de prácticas compartidas. Sería como si intentásemos construir el término "imagen sacra" como un duplo <pieza de madera, reacción de plegaria> sin aludir a todo el complejo de conceptos que están implicados en los rituales religiosos.

El segundo paso en el programa del realismo procedimental es el criterio de "asentimiento reflexivo" (en el caso de Rawls, el test de "equilibrio reflexivo") cuya función es elevar a público lo que de otra manera podría contemplarse como una pura reacción privada de proyección sobre el mundo de una reacción moral idiosincrásica sin fuerza normativa. El constructivismo necesita convertir las razones privadas en razones públicas. Para ello es bien conocido que el constructivismo acude a un procedimiento que se debe caracterizar en términos puramente formales, pues en otro caso no podría alcanzar la necesaria generalidad que define lo público. Corbí objeta que hay una tensión difícil de resolver entre el proyectivismo (o no realismo) moral y el carácter formal del principio de publicidad: si el constructivista mantiene su lealtad al proyectivismo, no logrará dar el paso de lo privado a lo público, y si mantiene su lealtad al formalismo, tendrá que acudir al mundo para resolver los desacuerdos en materia moral. $\mathrm{Su}$ objeción es que en casos de discrepancia sobre una situación, no es posible determinar si el desacuerdo es moral si no es a través de una red de conceptos morales que solamente se puede poner en acción acudiendo al propio mundo como respaldo. Para rastrear los rasgos morales de una situación en una discusión, el criterio puramente formal es insuficiente sin atender a la disciplina narrativa que entrañan nuestras prácticas en el marco de esta situación. La posibilidad del espacio público exige una confianza en el mundo de una manera que el proyectivismo no puede otorgar. La estrategia de Corbí pertenece a la familia wittgensteiniana en epistemología: ciertos modos de aislarse del mundo suponen la imposibilidad de discrepar. Los desacuerdos y debates escépticos pierden sentido y razonabilidad si no confían en el mundo de algún modo ${ }^{2}$ y este juego de posible discrepancia contra el marco de una confianza básica no puede darse si el criterio

${ }^{2}$ En On Certainty: "Realmente quiero decir que un juego del lenguaje sólo es posible si confiamos en algo (no dije podemos confiar en algo)" (Wittgenstein 1991, $\S 509)$. La confianza en el mundo que Wittgenstein propone como condición de conocimiento no es exactamente la misma que la que plantea Corbí, que tiene una 
es puramente formal. Esta confianza es la que está implicada en la disciplina narrativa con la que aplicamos la red de conceptos morales.

Hagamos un balance de los pasos contados: frente al modelo constructivista que exige que el juicio moral convierta una reacción en máxima mediante la distancia de lo particular, Corbí objeta casos de daño que no pueden entenderse como tales sin la presencia de un tercer agente que debe rastrearse en las características peculiares de la situación. Pero no podríamos hacerlo si la situación no tuviese rasgos morales en los que confiar para explicitar la naturaleza de este tercer agente. Este realismo moral se debe a que solamente podemos describir la situación mediante una red de conceptos sometidos a una disciplina narrativa. No está claro, sin embargo, que esta estrategia implique necesariamente una discusión ontológica sobre la naturaleza de las propiedades morales. Sería discutible cuánta realidad nos procuran las ideas de la indispensabilidad de redes de conceptos de nivel moral y de disciplina narrativa. Ciertas formas de realismo interno "a la Putnam" serían compatibles con ella. Lo que me parece que quiere defender Corbí es en un sentido más débil que lo implicado en la controversia del realismo, aunque en otro sentido es mucho más fuerte: se trata de la idea de que el juicio moral solamente es posible si la distancia del sujeto deliberante no es tan grande como para separarlo de la situación que juzga, porque entonces se producirán puntos ciegos, como los que impiden ver a los terceros agentes que están involucrados en la calificación de daño. Esto nos lleva a un siguiente paso de la discusión con el constructivismo, la naturaleza del agente moral.

Para elevar a principio un juicio o decisión, sostiene el constructivismo, el agente debe ser capaz de distanciarse de sí, de sus disposiciones, actitudes reactivas y rasgos de carácter para atender solamente al contenido generalizable del juicio moral. El punto en discusión es si esta distancia es simplemente un ejercicio de deliberación o implica, además, cierta tesis sobre la naturaleza del sujeto. Todo sujeto posee cierta capacidad de distancia de sí encarnada en sus capacidades cognitivas de reflexión y autocontrol; ahora bien, no está claro que su ejercicio sea necesario para la constitución del sujeto como agente moral. Nos encontramos aquí ante una doble discusión que en cierta forma se articula en un nuevo eje: por un lado, la cuestión de la naturaleza del sujeto moral dada esta capacidad de distancia, por otro

dimensión esencialmente moral (para Corbí, el sujeto confía en quienes harán de su mundo un "mundo humano"), pero esta restricción que sugiere el libro no es incompatible con la wittgensteiniana, y me atrevo a pensar que el horizonte de $O n$ Certainty daría mayor fuerza epistemológica a su posición. 
lado, la cuestión de si es necesaria la actitud reflexiva distante en la elaboración del juicio moral. La primera es una cuestión de agencia y ontología del sujeto; la segunda, una cuestión de epistemología moral.

Tal vez el constructivismo kantiano haya sido la tradición más comprometida con la relación entre la constitución del sujeto y la deliberación moral. Christine Korsgaard cree que la constitución del sujeto moral se produce por su identificación con su identidad práctica, entendida como "una descripción bajo la que encuentras tu vida digna de ser vivida y tus acciones dignas de ser emprendidas" (Korsgaard 1996, p. 101). Corbí concede este punto al constructivismo pero objeta que su programa de unificación del sujeto sólo se puede sostener sobre la inconsistente base de lo que califica como una "concepción dividida del yo" causada por la distancia reflexiva entre las disposiciones psicológicas y los principios morales o, en términos de Korsgaard, entre las identidades prácticas y la identidad moral. Las identidades prácticas se transmutan en identidad moral cuando el sujeto reconoce el principio de universalidad implicado en sus disposiciones. Solamente en la razón, sostiene Korsgaard, se produce la auténtica unificación del sujeto. ${ }^{3} \mathrm{El}$ argumento es, pues, que el constructivismo únicamente puede unificar al sujeto moral sobre la base de una más profunda división entre la identidad práctica y la identidad moral, entre las disposiciones y los principios.

El problema de la unidad de la filosofía moderna nacía de la división en facultades: razón y pasión, para Hume, o percepción, intuición, entendimiento y razón para Kant. Desde la escuela contemporánea de la sospecha, sin embargo, el sujeto aparece dividido entre lo que se manifiesta explícitamente y lo que actúa implícita y subcognitivamente. Toda la filosofía de la acción contemporánea se ha preocupado por este problema, que se manifiesta en formas dañadas de agencia como el autoengaño, la akrasia o la mala fe sartriana, en las que se desvela una tensión interna entre partes del yo que actúan en niveles diferentes de conciencia. Corbí sabe que no puede evitar este problema. Su estrategia se dirige a mostrar que, en primer lugar, la división kantiana entre disposiciones y reflexión no lo resuelve $\mathrm{y}$, en segundo lugar, que el problema no se puede solucionar

3 "El propio principio de razón, en contraste con todos los otros, es el principio que unifica verdaderamente el espíritu y lo unifica de modo que lo hace capaz de acción efectiva. Tanto Platón como Kant piensan que este principio, el que realmente nos unifica y convierte en autónomos, es también el principio de la persona moralmente buena" (Korsgaard 2009, pp. 175-176, citado en Corbí 2012, p. 132; todas las traducciones de las citas de esta obra son mías.) 
declarativamente; en todo caso, puede entenderse como una constricción a la que el sujeto puede enfrentarse terapéuticamente mediante una actitud expresiva. Corbí se enfrenta a este nuevo problema de la división en conversación con el análisis de la culpa que presenta Wollheim (1999). Para este autor, la culpa no es una emoción que surja simplemente por haber transgredido un principio, sino una reacción ante un agente implícito que podría acusarnos de haberlo hecho. Al igual que la vergüenza, que se origina por una exposición real o imaginada a la mirada pública, la culpa tiene, pues, una genealogía exógena. Siguiendo la tradición psicoanalítica, la culpa se generaría por un juego entre el proyectarse en la figura externa del padre y la introyección de esta figura en la forma de un dispositivo oculto de "acusación" generador de la culpa. Corbí modula este análisis en sus propios términos. La figura introyectada es la de la autoridad que protege al sujeto y hace humano su mundo, pero que también puede acusarlo y castigarlo. Se crea así un problema de división entre la autoridad internalizada y el miedo oculto a ser acusado. Es, de nuevo, una tercera voz que está operando, a veces subcognitivamente, en los juicios morales. La escisión ya no es, pues, entre principios y disposiciones, sino entre principios, disposiciones y la voz internalizada de la autoridad. En algunos casos esta estructura desvela comportamientos erróneos. El caso más claro es el que mostraron los experimentos de Milgram de obediencia a la autoridad por encima de la conciencia de los principios morales. En estos experimentos, sostiene Corbí, el miedo a la autoridad operaba por debajo de la conciencia moral de la situación: la figura introyectada aparecía distorsionando gravemente el juicio. Y este análisis, añade, puede aplicarse a numerosos casos de masacres o daños graves en los que el miedo hace que los sujetos se nieguen a reconocer la culpa, porque se sentirían amenazados por la autoridad interna. Pueblos enteros padecen esta distorsión en tales casos, como ha mostrado reiteradamente la historia. El razonamiento de los sujetos en los casos de Milgram de que aquéllo era un mero experimento estaba destinado a evitar la culpa como acusación de una autoridad introyectada que, de ocurrir, amenazaría el "mundo humano" de tales sujetos.

Se nos presenta así la división del sujeto mediante un análisis etiológico más que lógico: el sujeto padece una forma de ceguera causada por su miedo a perder su "mundo humano". Declarativamente, el sujeto emite un juicio pero tal preferencia expresa una ruptura interna entre su identidad y las figuras de autoridad introyectadas, es decir, una debilidad de su carácter. Es mejor no ver que sentirse amenazados por la situación. La actitud deliberante y deliberativa del 
sujeto kantiano es compatible, pues, con formas de ceguera moral que expresan también una opacidad con respecto a los mecanismos operantes en la deliberación.

Frente al modelo de sujeto de principios, Corbí suscribe la alternativa del carácter como un lecho sobre el cual asentar la unidad del sujeto. Se encuentra en compañía de una larga tradición que va desde Aristóteles hasta la reciente teoría de las virtudes (morales y epistémicas). Sabemos, sin embargo, que el recurso al carácter no carece de problemas ni del peligro del yo dividido. Varios autores han señalado la aparente contradicción entre el recurso al carácter y los datos empíricos del comportamiento de los sujetos (Doris 2002, y Harman 1998). John Doris, por ejemplo, sostiene que el registro experimental de la psicología social sugiere que deberíamos concebir la personalidad como una asociación de rasgos psicológicos de carácter local muy adaptados a situaciones específicas (Doris 2002, p. 64). Los partidarios del carácter se encontrarían entonces también ante un dilema: si acuden al carácter como un complejo unificador de la personalidad del sujeto, se enfrentan al oportunismo y la inconsistencia que muestran los sujetos en las situaciones particulares; si, por otro lado, aceptan que los rasgos de carácter son patrones de alcance muy específico, tendrán problemas para resolver la unificación del sujeto. Corbí tiene cerrado el camino a una solución reflexiva como propone el constructivismo, pues implicaría reconocer que el precio de la unificación es la distancia del propio carácter y, por consiguiente, la recaída en la concepción dividida del yo. Al mismo tiempo reconoce que "el agente debe centrarse en el caso particular pero de tal modo que se sienta forzado a proyectarse en otros casos similares" (p. 136, las cursivas son del original). Esta capacidad es una necesidad de su propuesta originada porque la disciplina narrativa de los conceptos morales impone la habilidad epistémica de proyectarse en otros casos ( $\sin$ caer en el universalismo, claro). El problema es el "quién" se está proyectando de situación a situación.

\section{El problema de la opacidad: epistemología y terapia}

Si el análisis del sujeto ha llevado a Corbí a una diagnosis etiológica, consecuentemente, la solución no puede ser metafísica sino terapéutica: la constitución moral del sujeto no es un a priori sino un proceso de cura y aprendizaje moral. El carácter es a la vez el problema y la solución: problema, porque expresa una división oculta; solución, porque puede hacer aflorar el mecanismo tácito. Pero, a) ¿cómo puede el sujeto constituirse como agente que se identifica con su 
propio juicio o decisión?, y b) ¿cómo puede resolverse la dispersión del carácter en rasgos desconectados? Corbí enfrenta dos formas de identificación: la puramente declarativa, que se encuentra en el mero "reconocimiento cognitivo" (recognition) de la identidad práctica del agente y la actitud práctica, expresiva, que supone un "reconocimiento práctico" (acknowledgment) de las propias disposiciones. Este reconocimiento práctico es el que propone la tradición psicoanalítica como logro terapéutico y según Corbí constituiría también un logro moral.

El sujeto escindido entre su capacidad reflexiva y sus disposiciones psicológicas, o entre sus declaraciones explícitas y sus mecanismos subcognitivos, sufre una opacidad que tiene consecuencias morales y no simplemente agenciales. Éste es el diagnóstico. Corbí propone varios ejemplos tomados de la literatura y el psicoanálisis en los que la declaración del sujeto oculta un estado mental (alguien que se oculta a sí mismo un estado, por ejemplo, un enamoramiento de otra persona que, de ser reconocido, le horrorizaría y que, no obstante, actúa causalmente sobre las decisiones o declaraciones explícitas del agente) o se propone un plan a sabiendas de que sus disposiciones psicológicas están en contra de su realización (el ludópata que declara que va a cambiar su conducta). El psicoanálisis considera estos casos como generadores de neurosis, y la tradición sartriana, como casos de mala fe; ambos los ven como ejemplos de agencia dañada. Tenemos así un problema de opacidad que restaura la simetría escéptica entre lo interior y lo exterior a la que había sido ciego el cartesianismo, creyente en que el escepticismo sobre el mundo externo se resuelve mediante la transparencia de los estados mentales propios como propiedad constitutiva de la agencia.

El autoconocimiento cartesiano supone la transparencia de los estados mentales propios como una constitución constitutiva. Pero esto es lo que está definitivamente sobre el tapete en el juego escéptico de la sospecha en torno a los mecanismos ocultos. Un primer paso en la propuesta de Corbí es introducir una distinción entre dos formas de transparencia (y por tanto de opacidad) de los estados mentales: la primera, detectada por Gareth Evans y recordada por Richard Moran, es la que liga "creer que $p$ " a " $p$ es verdad" y estipula (wittgensteinianamente) que un estado mental "mira hacia afuera" (Moran 2001). La segunda, no reconocida suficientemente en el influyente análisis de Moran, es la que abre la declaración del estado mental a las disposiciones psicológicas reales del sujeto. ¿Cómo se pueden conectar ambas, es decir, la declaración verbal y la disposición real? Moran 
sostiene que existen dos actitudes, una meramente teórica y una actitud práctica que resolvería esta conexión. Ahora bien, ¿por qué una actitud práctica haría permeable lo psicológico y lo teórico? Una mera decisión puede ser tan ciega como una declaración teórica. Está aquí implicado el problema de la unidad del sujeto. Una pura decisión que no surja de la identidad no es suficiente; una mera declaración que no conecte con la capacidad real práctica no es necesaria.

Consciente de este problema, y original en su planteamiento, Corbí, en un segundo paso, acude a la manera en que Bernard Williams concibe la idea de reconocimiento práctico. Williams propone que, en esta actitud, el sujeto se identifica con la autoridad de la identidad propia, y que esta actitud está entre el descubrimiento y la decisión (Williams 2002, p. 203), es como si el sujeto "hubiera sido forzado a reconocer la autoridad de su identidad como algo que da estructura y enfoque a su vida y su mirada" (Williams 2002, p. 203, citado en Corbí 2012, p. 172). Corbí sigue aquí a Williams en que la autoridad de la primera persona está en el entrecruce del descubrimiento y la decisión bajo la metáfora de "ser forzado". El sujeto se expresa con autenticidad en tanto que el reconocimiento de su identidad lo obliga a una cierta declaración o decisión. Uno de los puntos más originales del libro es el modo en que Corbí expande esta idea de Bernard Williams que, por su parte, es ya un paso adelante en el giro práctico que ha propuesto Richard Moran para tratar el autoconocimiento.

"Ser forzado" invoca connotaciones de heteronomía, pero ¿qué ocurre cuando es la identidad propia la que está en la base de esta fuerza? O bien consideramos que la verdadera identidad es, al modo kantiano, la que establece el reconocimiento de los principios o, como propone Corbí, la fuerza proviene de una forma de "receptividad pasiva" cuya propuesta originaria se encuentra en Simone Weil, en la forma de una obediencia a las demandas de la propia identidad. Existe cierta forma de necesidad que nace de la atención a las relaciones de las cosas: "actuar no por un objetivo sino desde una necesidad. No puedo hacerlo de otra forma. No una acción sino una suerte de pasividad. Acción inactiva" (Weil 1963, p. 39, citado en Corbí, p. 175). Esta obediencia pasiva podría entenderse como un sometimiento a un sistema de fuerzas que sería el del "verdadero yo", pero también, como propone Corbí en una luminosa metáfora, como una danza que, obedeciendo a la música, siguiera también los ritmos de las reacciones propias, en una especie de pasividad creativa entre las demandas de lo real y las producciones del propio yo. Así, sugiere, se podría generar una permeabilidad de las propias disposiciones a 
las deliberaciones conscientes de la situación, similar al modo en el que el cuerpo se somete a la música y al tiempo que se expresa en la danza. En esta metáfora de la danza se recoge también el papel terapéutico que el psicoanálisis atribuye a la expresión de las motivaciones ocultas. No como un simple reconocer declarativo, sino como un reconocimiento práctico que haría aflorar, en el caso de la culpa, las voces de las autoridades introyectadas y que no habrían reconocido por una mera actitud declarativa. Tendríamos de esta forma un modo distinto de abordar la cuestión de la unidad del sujeto: no desde un control reflexivo, sino desde una expresión terapéutica de las propias disposiciones.

Queda por responder, sin embargo, la cuestión empírica acerca de la localidad del carácter que suscitan los argumentos de John Doris. La conciencia expresiva que propone Corbí haría emerger las disposiciones internas, pero ¿en qué medida estas disposiciones, por permeables que sean a la deliberación a través de la conducta expresiva, permiten generar patrones estables de respuesta moral que no sean puras reacciones locales dependientes de la situación? Doris sostiene:

[el] situacionismo amenaza con el escepticismo sobre el "poder del razonamiento práctico"; desde mi punto de vista, el registro empírico problematiza las concepciones familiares de racionalidad práctica. Es verosímil que el razonamiento práctico proficiente sea contextualmente variable de formas sorprendentes (o como yo digo, sea "fragmentado"). A veces la gente se aproximará a la sabiduría en ciertas situaciones pero no en otras, aun cuando las situaciones sean bastante similares. (Doris 2005, p. 659; todas las traducciones de las citas de esta obra son mías.)

Ésta es una objeción que afecta directamente la constitución moral sobre el carácter del agente, al menos conforme a cierta descripción que Doris califica de "globalista". Las psicologías morales globalistas, afirma, son aquellas que se distinguen por la idea de que la conducta está organizada por rasgos robustos y por el presupuesto de que "si una persona tiene un rasgo robusto cabe esperar confiablemente que manifieste una conducta en la que el rasgo sea pertinente a través de una variedad de situaciones en las que el rasgo sea pertinente incluso cuando alguna de ellas o todas no conduzcan de modo óptimo a tal conducta" (Doris 2002, p. 18). Nomy Arpaly presenta como ejemplo una persona que es valiente en una situación de conflicto físico, pero que no lo es ante su pareja o que se muestra incapaz de hablar en 
público (Arpaly 2005). Acudir a un rasgo de carácter como la valentía no nos ayuda a explicar las variaciones tan normales de conducta como ésta del ejemplo. ¿Podría acaso la propuesta de Corbí encontrar una respuesta? ¿En qué medida el situacionismo no amenaza también a la normatividad moral de la actitud expresiva? Estas preguntas nos llevan a otra relacionada con ellas: ¿en qué medida es terapéutica una actitud deliberativa? Pues "terapia" hace referencia a una situación estable de salud y, por ello, a un funcionamiento adecuado de las facultades.

Peter Goldie afirma con perspicacia que es inútil responder a la objeción empírica poniendo en duda los datos (Goldie 2007). Habría que admitir el carácter fragmentario de la constitución humana y hacerse cargo de ella encontrando alguna forma de explicar, sin embargo, por qué aún podemos seguir postulando que hay una distinción entre quienes simplemente reaccionan a una situación y quienes perciben y conocen que en ella están implicados problemas morales. El situacionismo en su forma escéptica tampoco nos permite explicar por qué en situaciones como las que examina el experimento de Milgram hubo algunos sujetos que se negaron a colaborar con la autoridad, de hecho el 14 por ciento, y percibieron el problema moral que está en juego. ¿Cómo es posible reaccionar con cierta clase de conductas que llamamos morales a cierta clase de situaciones?

Si la fragmentación del carácter tiene visos de ser una hipótesis plausible, la robustez suficiente para sostener la conducta moral se debe encontrar por otra vía. Corbí dispone de un recurso suficiente, la disciplina narrativa, de hecho compatible con la "integración narrativa" que propone Doris (Doris 2002, p. 142). El sujeto debe proyectarse de situaciones parecidas a situaciones parecidas ${ }^{4}$ y para ello debe tener suficientes habilidades epistémicas que le permitan reconocer lo similar de las situaciones. ¿Cómo integrar esta vía con la atención expresiva?

\section{El problema del daño: la voz de la víctima y el tercer agente}

Uno de los logros de esta obra es el tratamiento que ofrece de los ejemplos, que en realidad aconseja una actitud metodológica al teórico de la moral. Son ejemplos densos narrativamente, tomados de

\footnotetext{
4 "La disciplina narrativa de los rasgos morales parece presuponer cierta habilidad epistémica de parte de los agentes, a saber, la habilidad para proyectar nuestra respuesta moral de uno a otro caso particular de modos que no llegan a lo que los principios universales parecen requerir, pero no caen en la voluntad particularista tal como Korsgaard la ha caracterizado" (Corbí 2012, p. 134).
} 
la literatura de ficción, documental o periodística, que presentan situaciones en las que el lector se ve involucrado emocionalmente pese a la distancia que se supone que existe entre el teórico y el lector. En un primer ejemplo, nos presenta el dilema de Primo Levi en Los caídos y los salvados. Levi confiesa haber sentido una vergüenza irreprimible por haber sobrevivido a Auschwitz, un sentimiento ante el que mantiene una actitud ambigua: en primera persona le es posible deliberar acerca de si es un sentimiento correcto, pero niega a cualquier otra persona no superviviente de los Lager el derecho a juzgar la corrección de su sentimiento. En un segundo ejemplo, siguiendo las entrevistas que Svetlana Alexievich realizó a los soldados rusos en la guerra de Afganistán (Alexievich 1992), se examina el imaginario de un soldado en tres momentos: el reclutamiento, la batalla y el retorno a casa. En un tercer ejemplo, tomado de Améry, debate sobre la pérdida de confianza en el mundo que sufre la víctima de la tortura. Se presentan otros ejemplos, de Musil y Freud, sobre el autoconocimiento, pero los tres anteriores manifiestan una clara voluntad de involucrar al lector en un examen de sus propios sentimientos al tiempo que delibera sobre las actitudes morales. Los ejemplos adquieren así fuerza demostrativa precisamente por su capacidad de echar abajo la distancia deliberativa y de activar actitudes reactivas que se ponen a prueba en el análisis que Corbí hace de la presencia de terceros agentes en los discursos justificativos que suceden a este tipo de ejemplos. Es una propuesta realmente profunda que nos hace pensar sobre la cuestión del soporte a la actitud moral sin acudir a un concepto de carácter omniexplicativo.

Estos ejemplos nos permiten examinar la cuestión pendiente de la naturaleza del agente moral. Todos ellos contienen el concepto de daño como sustrato del juicio moral. En la construcción del concepto se expresan las reacciones definidas por exclamaciones como "esto no tendría que haber ocurrido" o "nunca más", que convocan a una calificación de daño y al compromiso moral. La aplicación del concepto a una situación de sufrimiento significa la introducción de un elemento de fuerza normativa, de cierta necesidad, un elemento que establece un vínculo fuerte entre las situaciones y el agente moral. En los tres ejemplos presentados, los terceros agentes aparecen como voces que distorsionan lo que aparentemente sería un juicio directo sobre la situación: en el caso de Levi, el autor, en primera persona, niega el derecho de terceros agentes a entrar en una conversación entre él y los supervivientes. En el segundo caso, los afgantsi (término popular para los soldados enviados a Afganistán) se desalientan cuando los terceros agentes, sus familiares, no quieren escuchar su 
relato porque los comprometería a aceptar su responsabilidad en los actos que tendrían que escuchar. En el tercer caso, la víctima, Améry, pierde la confianza en el mundo al no encontrar a los terceros agentes que deberían haberlo protegido o, al menos, ahora, encargarse de hacer justicia. Corbí nos advierte con toda razón que la construcción del juicio del daño no puede realizarse sin atender al lugar de estos terceros agentes, porque su voz o su silencio.

¿Cómo se articula entonces la constitución del agente moral, su capacidad de juicio y de proyección en situaciones de daño en las que las voces de los terceros agentes pueden producir distorsiones? Corbí nos facilita algunas claves: por un lado, la atención, en cuanto que actitud de relación intensa con la situación particular, pero también como reacción expresiva de las disposiciones propias. Por otro lado, la capacidad de proyectar e introyectar figuras de autoridad, que ha tomado del análisis que Wollheim hace de la emoción de culpa. En tercer lugar, al analizar los rasgos morales de las situaciones, estipula la necesidad de una disciplina narrativa para discriminar tales rasgos en una situación que, de otra forma, se podría haber descrito en puros conceptos conductistas sin significado moral. Pero, ¿̨cómo se relacionan estos tres elementos de tal forma que inyecten el suficiente grado de necesidad en el juicio de daño?

La idea de disciplina narrativa puede ejercer aquí una función determinante; sin embargo, Corbí no ha desarrollado todo su potencial en relación con la constitución del sujeto y la capacidad de atención y actitud expresiva. Aparentemente éstas sólo están conectadas como una constricción que se impusiera heterónomamente a las actitudes reactivas de los agentes. La relación no puede estipularse en términos de carácter, pues este concepto abarca muy poco para sostener una proyección robusta entre situaciones de daño, ni tampoco en forma de principios, dado que el concepto de principio abarca demasiado para el objetivo de Corbí. Me atrevo a sugerir que la idea de disciplina narrativa tiene virtualidades que, pueden explotar como concepto que vincularía la constitución del sujeto y las clases de situaciones de daño.

Adriana Cavarero (2000) explica que la constitución del yo es resultado de incorporar a las narrativas propias los relatos que los otros hacen de uno mismo. ${ }^{5}$ Es una propuesta profunda que vincula la identidad narrativa con la introyección de la voz del otro en la autoconstitución, que adquiere de este modo una estructura polifónica. La figura de terceros agentes adquiere, bajo esta luz, un poder

\footnotetext{
${ }^{5}$ Véase también Thiebaut y Aramburu 1992.
} 
constitutivo que ayudaría a aclarar algunas dudas en el proyecto de Corbí. Los terceros agentes aparecen como voces (a veces mudas) que están presentes en el relato que permite entender la situación. Pero estos relatos de situaciones no son contingencias externas en la historia moral del agente sino procesos constitutivos. Daniel Hutto y Peter Goldie (Hutto 2008 y Goldie 2012) han defendido la centralidad constitutiva de los relatos en la capacidad de entender a los otros. La tesis narrativista de Hutto y Goldie es que los relatos llegan a donde las actitudes reactivas modeladas por nuestras prácticas no alcanzan. Las prácticas configuran actitudes reactivas que cambian de una situación a otra (son compatibles, por lo tanto, con la idea de carácter fragmentado), pero en las situaciones "extrañas", es decir, en aquellas que necesitan que el sujeto se involucre de manera extraordinaria, son los relatos los que nos confieren instrumentos de apropiación. Los relatos, desde esta perspectiva, no son estructuras contingentes de situaciones que se articulan ficticiamente, sino depósitos de experiencia que configuran las trayectorias de aprendizaje de los sujetos.

La idea de daño, la voz de la víctima, la del tercer agente y la constitución del sujeto, siguiendo esta propuesta, se articularían mucho mejor con la idea de atención que propone Corbí si entendiéramos ésta en forma narrativa como "atención a un relato". Más que las connotaciones visuales, la atención se aclara mucho mejor si la entendemos conforme a la idea de política de voces. La idea de "voz", nos explica de nuevo Cavarero (2005), tiene el poder de lo particular, pues la voz es por naturaleza singular, y al mismo tiempo comunica contenidos que podemos entender al escuchar su relato e introyectarlo, entenderlo. Entender un relato implica una relación de escucha, de intelección, aunque también y, sobre todo, de apropiación y de involucramiento en él. Para decirlo con otros términos, la voz nos transporta a un escenario de segunda persona donde el yo y el otro no pueden permanecer indiferentes sin negar todo vínculo moral que nace del reconocimiento práctico de sus respectivas voces. José Medina (2013) ha explicado cómo las voces de las víctimas pueden llegar a transformar la epistemología del espacio público a través del poder performativo que implican sus reclamaciones de justicia, y con ello llegar a transformar también las reacciones y las constituciones de los sujetos que habitan ese espacio.

La disciplina narrativa que propone Corbí aparece de este modo como el problema y como la solución a la cuestión de la unidad del agente. Mas para ello debe abandonarse un modelo de agente aún demasiado comprometido con el soliloquio y la voz interior, 
que parece desprenderse del modelo psicoanalítico del sujeto en el diván que está presente como un fantasma en la propuesta de Corbí. Pensar en un sujeto constituido polifónicamente por las voces que ha aprendido a escuchar (y no sólo a oír como ruido ambiente) nos lleva a un escenario en el que los "nunca más" se pueden concebir como voces de víctimas que ya nunca dejarán de escucharse en un relato sin provocarle al sujeto inestabilidades emocionales.

En todo caso, esta sugerencia está ya implícita en el programa particularista de Corbí, que desarrolla en esta obra un ejemplo de cómo escribir teoría moral sin moralismo, sin adoctrinamiento y, sobre todo, sin esa distancia académica que esconde también un tedio no disimulado ante las cuestiones más profundas del mundo humano. Morality, Self-Knowledge and Human Suffering es también una obra que aporta una sensibilidad y una voz que me atrevería a calificar de "mediterráneas" en una conversación sobre moral en la cual han dominado tonos más austeros y distantes. ${ }^{6}$

\section{BIBLIOGRAFÍA}

Alexievich, Svetlana, 1992, Zinky Boys. Soviet Voices from the Afghanistan War, Norton, Nueva York.

Arpaly, Nomy, 2005, "Comments on Lack of Character by John Doris", en "Book Symposium on Lack of Character", Philosophy and Phenomenological Research, vol. 71, no. 3, pp. 643-646.

Benhabib, Seyla, 1992, "The Generalized and the Concrete Other: The Kohlberg-Gilligan Controversy and Moral Theory", en Situating the Self: Gender, Community and Postmodernism in Contemporary Ethics, Routledge, Nueva York, pp. 148-177.

Benhabib, Seyla y Drucilla Cornell (comps.), 1987, Feminism as Critique, Polity Press, Londres.

Cavarero, Adriana, 2005, From More than One Voice. Toward a Philosophy of Vocal Expression, Stanford University Press, Stanford. Londres.

Dancy, Jonathan, 2009, "Moral Particularism", The Stanford Encyclopedia of Philosophy (Invierno 2009) <http://plato.stanford.edu/entries/ moral-particularism/> [última consulta: 12-11-2013].

Doris, John, 2005, "Replies: Evidence and Sensibility", en "Book Symposium on Lack of Character", Philosophy and Phenomenological Research, vol. 71, no. 3, pp. 656-677.

${ }^{6}$ Este trabajo se ha beneficiado del proyecto FFI-2011-25131 del Gobierno Español. Agradezco también los comentarios previos de Carlos Thiebaut y José Medina. 
Doris, John, 2002, Lack of Character: Personality and Moral Behavior, Cambridge University Press, Nueva York.

Goldie, Peter, 2012, The Mess Inside. Narrative, Emotion and the Mind, Oxford University Press, Oxford.

_- 2007, "Review of Lack of Character", Journal of Moral Philosophy, vol. 4, no. 2, pp. 290-293.

Harman, Gilbert, 1998, "Moral Philosophy Meets Social Psychology: Virtue Ethics and the Fundamental Attribution Error", Proceedings of the Aristotelian Society, vol. 99, no. 1, pp. 315-331.

Hutto, Daniel, 2008, Folk Psychological Narratives. The Sociocultural Basis of Understanding Reasons, MIT Press, Cambridge, Mass.

Korsgaard, Christine M., 2009, Self-Constitution: Agency, Identity, and Integrity, Oxford University Press, Oxford.

, 1996, The Sources of Normativity, Cambridge University Press, Cambridge. [Versión en castellano: Las fuentes de la normatividad, Instituto de Investigaciones Filosóficas-UNAM, México, 2000.]

Lewis, David, 1989, "Dispositional Theories of Value", en Papers in Ethics and Social Philosophy, Cambridge University Press, Cambridge, pp. 68 94.

Medina, José, 2013, Epistemology of Resistance. Gender and Racial Opression, Epistemic Injustice and the Social Imagination, Oxford University Press, Oxford.

Moran, Richard, 2001, Authority and Estrangement. An Essay on SelfKnowledge, Princeton University Press, Princeton.

Putnam, Hilary y Jürgen Habermas, 2008, Normas y valores, introd., trad. y notas Jesús Vega y Francisco Javier Gil, Trotta, Madrid.

Rawls, John, 1999, A Theory of Justice, Oxford University Press, Oxford.

Thiebaut, Carlos y Antonio Aramburu, 1992, "The Complexity of the Subject, Narrative Identity and the Modernity of the South", Philosophy and Social Criticism, vol. 18, nos. 3-4, pp. 313-331.

Weil, Simone, 1963, Gravity and Grace, Routledge, Londres.

Williams, Bernard, 2002, Truth and Truthfulness, Princeton University Press, Princeton.

Wittgenstein, Ludwig, 1991, On Certainty, John Wiley and Sons, Londres.

Wollheim, Richard, 1999, On the Emotions, Yale University Press, New Haven y Londres.

Recibido el 4 de enero de 2013; aceptado el 4 de octubre de 2013. 